\title{
The high dose of vitamin D supplementation combined with yoga training improve the leukocytes cell survival-related gene expression in breast cancer survivors
}

\author{
Vahid Khedmati Zare ${ }^{1}$, Maedeh Javadi ${ }^{1}$, Sadegh Amani-shalamzari ${ }^{1 *}$ (1) and Mojtaba Kaviani ${ }^{2}$
}

\begin{abstract}
Background: This study aimed to examine the effect of yoga training combined with vitamin D supplementation on the expression of survival-related genes in leukocytes and psycho-physical status in breast cancer survivors.

Methods: Thirty breast cancer survivor women (age, $48 \pm 8 \mathrm{yrs}$ ) were randomly assigned into three groups: high dose (4000 IU) of vitamin D supplementation (HD) $(n=10)$; yoga training with a high dose of vitamin $D(Y+H D)$; $(n=10)$; yoga training with a low dose (2000 IU) of vitamin $D(Y+L D)(n=10)$. Participants performed the Hatha yoga style twice a week. Blood samples and a battery of psychological and physical tests were taken before and after the completion of interventions. Expression of $\mathrm{p} 53, \mathrm{NF}-\mathrm{kB}, \mathrm{BCl} 2$, and Bax genes was measured in leukocytes.

Results: Body fat percentage ( $n p 2=0.36)$, shoulder flexibility $(n p 2=0.38)$, Rockport walk tests $(n p 2=0.49)$, and anxiety $(n \mathrm{p} 2=0.52$ ) were significantly improved in both the $Y+\mathrm{HD}$ and $\mathrm{Y}+\mathrm{LD}$ groups compared to the HD group $(p<0.05)$. P53 was significantly over-expressed in the $Y+H D$ group while $B c l 2$ upregulated in both the $Y+H D$ and $Y+L D$ groups. NF-KB and Bax expression downregulated in all groups but were not statistically significant.

Conclusion: yoga training combined with low and high doses of VD improved physical fitness and psychological measures while only in combination with a high dose of VD positively modified the leukocytes cell survival-related gene expression.
\end{abstract}

Keywords: Physical activity, Immune system, Flexibility, NF-kB, p53, Bcl2/Bax ratio

\section{Introduction}

Breast cancer (BC) treatments such as chemotherapy and radiotherapy typically cause side effects on psychological, physical, and physiological health in patients. Research has shown that BC survivors are at higher risk of developing psychiatric disorders, especially depression, stress, and anxiety [1], as well as impairment of the physical performance, such as strength and aerobic fitness [2].

*Correspondence: amani_sadegh@khu.ac.ir

${ }^{1}$ Department of Exercise Physiology, Faculty of Physical Education and Sports Science, Kharazmi University, Tehran, Iran

Full list of author information is available at the end of the article
In addition, some of the physiological functions of $\mathrm{BC}$ survivors, such as immune responses, are impaired by cancer treatments $[3,4]$. Immunosuppression is one of the significant side effects of BC treatments [5]. A study reported that recovery of numerous immune parameters following $\mathrm{BC}$ therapies is delayed; hence, attenuated immune systems are involved in the recurrence of the disease and prolong cancer recovery [5].

Immune cell survival is a highly sophisticated process regulated by the balance between apoptotic and antiapoptotic genes. P53 is an anti-apoptotic gene that promotes cell survival by inducing reversible cell cycle arrest original author(s) and the source, provide a link to the Creative Commons licence, and indicate if changes were made. The images or other third party material in this article are included in the article's Creative Commons licence, unless indicated otherwise in a credit line to the material. If material is not included in the article's Creative Commons licence and your intended use is not permitted by statutory regulation or exceeds the permitted use, you will need to obtain permission directly from the copyright holder. To view a copy of this licence, visit http://creativecommons.org/licenses/by/4.0/. The Creative Commons Public Domain Dedication waiver (http://creativeco mmons.org/publicdomain/zero/1.0/) applies to the data made available in this article, unless otherwise stated in a credit line to the data. 
[6]. P53 regulates immune cells' function; however, p53 activity in leukocytes of $\mathrm{BC}$ survivors has not been studied. It was reported that the loss of p53 in the immune cells of rodents leads to increased susceptibility to tumor growth [7]. On the other hand, NF-kB is a crucial regulator of several biological processes such as immunity, inflammation, and apoptosis, which could upregulate various pro-inflammatory and cell death genes [8]. NF- $\kappa B$ translates stress into inflammation and is a link between inflammation and cancer [9]. It is involved in the cell apoptosis process via suppressing the anti-apoptotic gene, $\mathrm{Bcl} 2$, and upregulating apoptotic gene, Bax; hence NF- $\mathrm{kB}$ decreases the $\mathrm{Bcl} 2 / \mathrm{Bax}$ ratio $[10,11]$. It was also reported that chemotherapy was associated with NF- $\kappa B$ activation in $\mathrm{BC}$ tissue and leukocytes [12], and enhanced NF- $\mathrm{KB}$ activity was paralleled with physical fatigue [12]. In contrast, P53 counteracts the effects of NF-kB [13] and increases cell survival by inducing reversible cell cycle arrest [6]. Therefore, the balance between NF-кB and p53 is involved in cell survival.

Complementary therapies, including nutrient supplements and exercise training, involve controlling gene expression and are a new approach to managing breast cancer symptoms. Cancer patients have been shown to be malnourished, which can lead to worsening their condition [14]. Thus, antioxidants [15] and vitamins [16] supplements are recommended for cancer patients. These supplements contain nutritious and polyphenolic compounds that could regulate genes' expression involved in inducing and progressing chronic diseases. Research has shown vitamin $\mathrm{D}(\mathrm{VD})$ deficiency is a common condition in women with the later-stage disease and those who received radiation therapy [17], which is associated with increased $\mathrm{BC}$ mortality rates $[17,18]$. Thus, most BC survivors receive different doses of VD. Vitamin D plays some physiological functions, such as cell cycle regulation, by affecting the p53 gene expression [19] and inhibits the activation pathway of NF-kB in human leukocytes $[20,21]$. Besides, VD plays a role in the cell survival cycle by regulating the $\mathrm{Bcl} 2 / \mathrm{Bax}$ ratio [22]. Research has shown that VD exerts a growth inhibitory effect on breast cancer cells, and the treatment of breast cancer cells with VD led to the upregulation of 51 genes, $40 \%$ of which were involved in the cell cycle and apoptosis [23]. It has been shown that a high dose of VD supplementation is safe and has favorable effects on insulin-like growth factor signaling with no significant change in mammographic density in women at higher risk of BC [24].

A non-pharmaceutical approach to mitigate the side effects of cancer and its treatments is physical activity. In systematic reviews, improvements in physical fitness and psychological health of cancer survivors with yoga were reported $[25,26]$. Yoga is a physical, mental, and spiritual exercise that integrates mind, body, and spirit to improve psychological and physical health by reducing stress [27]. Yoga exercises include physical exercises (asanas), breathing techniques (pranayama), and meditation (Dyana). Yoga has recently been adapted as a complementary treatment to reduce chronic disease-induced stress [28], especially for BC-related mental health complications. BC-related chronic stress has been shown to induce chronic inflammation, leading to the suppression of the immune system. Mechanistically, T lymphocytes were suppressed through a high cortisol level [29], potentially delaying the treatment process. Knowingly, yoga therapies could reduce inflammatory responses [30] and improve various immunological parameters of cellular immunity [31]. Still, the molecular mechanisms of these benefits are poorly understood. It was demonstrated that yoga intervention might downregulate NF- $\mathrm{KB}$ in leukocytes of dementia patients [32], yet, the molecular mechanisms and yoga practice on the immune cells in $\mathrm{BC}$ survivors are unclear.

Recent studies have suggested the possible involvement of exercise training in reducing the side effects of high doses of antioxidant supplementation in breast cancer tumors [33]. However, considering the immune system's responses, the impact of simultaneous exercise training and a high dose of VD intake on leukocyte survival in BC survivors have not been elucidated. Overall, given that a high dose of vitamin $\mathrm{D}$ is safe for women at higher risk of $\mathrm{BC}$ [24] and recommended for $\mathrm{BC}$ survivors to reduce inflammatory markers; yoga also has a substantial effect on this process; we hypothesized that combining yoga exercise training and high VD dose could modulate the gene expression involved in the survival of immune cells and improve the immune system of BC survivors. Moreover, we examined whether the combination of yoga training and low VD dose could have the same beneficial effects. At last, we assessed the effects of these interventions on anthropometric, physical, and psychological features.

\section{Materials \\ Study design}

In a randomized trial with pre and post-test, the effectiveness of a 12-week yoga training with VD supplementation was examined. Eligible BC survivors were recruited to take part in the study under the supervision of their physicians. A week before the intervention, VD levels and pre-tests were completed, and physicians selected qualified individuals. Then, randomization based on the initial VD levels was conducted by the third person who was not in the research group. Before and after the intervention, blood sampling, anxiety questionnaire, and physical fitness tests including, Rockport walk and 
handgrip strength tests, were measured. Gene expression of P53 and NF-kB were measured in blood samples.

\section{Participants}

Breast cancer survivors referred to Shohadaye Tajrish hospital (Tehran, Iran) were contacted for this study. Survivors who had completed chemotherapy and radiotherapy five years ago and were exposed to hormone therapy, and did not have any acute medical conditions (cardiovascular diseases, diabetes) were eligible to participate. Also, individuals were selected who did not have any experience of yoga training and had a high-dose VD supplementation, and were physically able to perform yoga exercises. Thirty-three $\mathrm{BC}$ survivor women who met the inclusion criteria volunteered to participate in the survey, but we only analyzed the data of 30 participants (age: $47.90 \pm 7.95$ years; height: $160.93 \pm 6.12 \mathrm{~cm}$, body mass: $72.62 \pm 11.72 \mathrm{~kg}$ ). One participant was excluded from the study due to a change in a medical situation; one did not participate in more than four consecutive training sessions, one failed to complete the post-test. Participants were randomly assigned into a high dose (4000 IU) of VD supplementation (HD) group $(n=10)$, yoga with a high dose (4000 IU) of VD (Y+HD) group $(n=10)$, and yoga with a low dose (2000 IU) of VD (Y+LD) group $(n=10)$. Due to ethical reasons, it was impossible to have a group that only practices yoga because $\mathrm{BC}$ survivors were prescribed to consume VD. After being informed of the benefits and risks of research, written consent was obtained from the participants. A sample size calculation was performed using G*Power Software version 3.1.9.6 (Düsseldorf, Germany) to determine the number of participants in each group. The estimated number of patients needed to assume a rejection criterion of 0.05 and 0.85 (1-beta) power and a large effect $(f=0.65)$ was ten persons per group, depending on the statistical test used. The Ethics committees approved all research procedures for the Sport Sciences Research Institute of Iran (approval number: IR.SSRI.REC.1398.111) were conducted under the Declaration of Helsinki.

\section{Vitamin D supplementation}

Participants in the HD and YHD groups received VD tablets containing 4000 IU daily, and those in the YLD group consumed 2000 IU daily. They have received a pack of 10 tablets every 10 days to take every day at a given time by receiving an alarm from the WhatsApp group.

\section{Yoga protocol}

Participants in the yoga groups performed yoga practice twice a week for 12 weeks. The duration of the yoga program started with 60-min and progressively increased to $90 \mathrm{~min}$ over the course. One certified yoga teacher conducted yoga sessions. Yoga exercises were selected from the Hatha yoga style and included asana (physical postures), pranayama (breath control), and Dyana (meditation). The yoga protocol is presented in Table 1. After each yoga session, the participants were asked to express their effort and exertion (the Borg rating of perceived exertion (RPE) scale (6-20 score)) of the yoga session [34]. As the training progressed, more complex and more challenging movements were selected, as well as the movements were repeated more to increase the load of workouts.

\section{Measurements}

\section{Physical measurements}

Anthropometric measures, including height and body mass, were measured using a height scale (Seca 206, Hamburg, Germany) and a digital body weight scale (Seca 803, Hamburg, Germany), respectively. Moreover, body fat percentage (BF \%) was estimated by measurement of subcutaneous fat of seven skinfold sites based on Jackson and Pollock's instructions [35] using a Lange skinfold caliper (beta Technology Inc., Cambridge, MD USA).

\section{Rockport walk test (RWT)}

The RWT test, a one-mile self-paced walking test, was used to measure aerobic fitness [36]. The test measures the time lasted to walk one mile as quickly as safely. Four cones were placed in the corners of the futsal court, and every meter was marked between the cones. Participants walked at a rate suitable to their fitness for one mile while wearing a polar heart rate monitor Polar RC3, Polar Electro Oy, Kempele, Finland), and they were allowed to stop or change their paces.

\section{Shoulder range of motion}

The range of active shoulder abduction in the side of surgery was measured by a Leighton flexometer (Spokane, WA, USA) [37]. Participants stood near a pillar, and their head, trunk, and hip were fixed with straps. A flexometer was attached to their arm; the dial at 0 degrees was considered when the hand hanged on the side of the body. Then, participants elevated their arms in the strict coronal plane as far as they could. At the end-range point, the measurement was documented. The best of the three trials was considered.

\section{Anxiety}

The Beck Anxiety Inventory (BAI) was used to assess anxiety [38]. The questionnaire consists of 21 items that evaluate the clinical symptoms of anxiety in the past month. All questions had a similar weight and score on a 
Table 1 Yoga protocol

\begin{tabular}{|c|c|}
\hline Pranayama & Breathing and moving (Yoga Mudra) \\
\hline Asana & Child's Pose (Balasana) \\
\hline Asana (Marjaryasana cycle) & $\begin{array}{l}\text { Cradle the leg Pose (Hindolasana), Cradle Pose knees } \\
\text { to chest (Hindolasana), bridge pose (Setu Bandha), } \\
\text { Cobra Pose (Bhujangasana), Child's Pose (Balasana), } \\
\text { Cradle Pose knees to chest (Hindolasana), Cow } \\
\text { Pose (Bitilasana), Cat Pose (Marjaryasana), Bird Dog } \\
\text { Pose (Parsva Balasana), Gate Pose (Parighasana), } \\
\text { Side Plank Pose Variations on knee (Vasisthasana), } \\
\text { Cow Pose (Bitilasana), Cat Pose (Marjaryasana), Hero } \\
\text { Pose (Virasana), Staff Pose (Dandasana), Corpse Pose } \\
\text { (Savasana) }\end{array}$ \\
\hline Pranayama & Respiratory coordination \\
\hline Asana & Like burpee (Surya namaskar or sun salutation) \\
\hline Asana & Bound Angle Pose (Baddha Konasana) \\
\hline Asana & Mill Churning Pose (Chakki Chalanasana) \\
\hline Asana & Chair Pose (Utkatasana) \\
\hline Asana & Reclining Bound Angle Pose (Supta Baddha Konasana) \\
\hline Asana & Cobra Pose (Bhujangasana) \\
\hline Asana (kriya cycle) & $\begin{array}{l}\text { Triangle Pose (Utthita Trikonasana), Waist Rotating } \\
\text { Pose Variation A Yoga (Katichakrasana), Big Toe Pose } \\
\text { (Padangusthasana), Mill Churning Pose (Chakki } \\
\text { Chalanasana), Staff Pose with front lateral raises } \\
\text { (Dandasana), Revolved Hero Pose Yoga (Parivrtta } \\
\text { Virasana), Cobra Pose (Bhujangasana), Boat Pose } \\
\text { (Paripurna Navasana) }\end{array}$ \\
\hline Asana & Locust Pose (Salabhasana) \\
\hline Asana & Half Wind Relieving Pose (Ardha Pavana Muktasana) \\
\hline Asana & Wind-Relieving Pose (Pavanamuktasana) \\
\hline Asana & Twisting Posture ( suptaVakra Asana) \\
\hline Dyana (meditation) & Corpse Pose (Savasana) \\
\hline
\end{tabular}

scale value of 0 (not at all) to 3 (severely). A higher score indicates a more severe anxiety level.

\section{Cortisol}

Blood samples were collected from the antecubital venous after 10 to $12 \mathrm{~h}$ of fasting between 7 and 8 am before and after the interventions. Blood samples were centrifuged at $3000 \mathrm{rpm}$ for $15 \mathrm{~min}$, and serum was separated from the blood samples using a suspension technic and stored at $\mathrm{a}-20{ }^{\circ} \mathrm{C}$ freezer until further biochemical analysis. Serum cortisol was measured using an enzymelinked immunosorbent assay (ELISA) kit (Monobind, Inc. Lake Forest, CA, USA).

\section{Gene expression}

Blood samples in tubes containing anticoagulants (EDTA) were centrifuged at $3000 \mathrm{rpm}$ in a $4{ }^{\circ} \mathrm{C}$ centrifuge for $10 \mathrm{~min}$. The buffy coat layer was removed from the blood samples using a suspension technic and stored at a $-70{ }^{\circ} \mathrm{C}$ freezer. RNA samples were isolated from buffy-coats (white blood cells-enriched blood samples) extracted using the total RNA extraction Kit (Takara,
Japan). The total RNA concentration was assessed using a NanoDrop ND-1000 (NanoDrop Technologies/Thermo Scientific, Wilmington, DE, USA), and cDNA synthesis was performed using the Takara cDNA synthesis kit (Takara, Japan) according to the manufacturer's instructions. Real-time PCR was performed using the SYBR Green Master Mix kit (Ampliqon, Denmark). The thermal cycling program was as follows: $94{ }^{\circ} \mathrm{C}$ for $5 \mathrm{~min}$ followed by 40 cycles of $95{ }^{\circ} \mathrm{C}$ for $30 \mathrm{~s}, 54^{\circ} \mathrm{C}$ for $45 \mathrm{~s}$, and $72{ }^{\circ} \mathrm{C}$ for $30 \mathrm{~s}$. We used GAPDH mRNA for the normalization of the gene expression analysis. The sequence of PCR primers used for the amplification of the proteincoding genes were as follow: p53 forward "TGACTGTAC CACCATCCACTA", p53 reverse "AAACACGCACCT CAAAGC"; NF-кB forward "CTTGGGTGCTGATGT CAATG", NF- $\mathrm{kB}$ reverse "GGAGAATAGCCCTGGTAG G"; BAX forward "TGACTGTACCACCATCCACTA" BAX reverse "AAACACGCACCTCAAAGC"; Bcl2 forward "CCCTGTGGATGACTGAGTAC" Bcl2 reverse "GAGAAATCAAACAGAGGCCG"; GAPDH forward "CCCTTCATTGACCTCAACTACATG" GAPDH reverse "TGGGATTTCCATTGATGACAAGC". The fold 
change expression was calculated using the REST-2009 software.

\section{Statistical analysis}

The Statistical Package of Social Sciences (SPSS, IBM, v19) was used to analyze the data; parametric data are expressed as mean \pm standard deviation (SD), and nonparametric data are expressed as median (25th-75th interquartile range). Analysis of covariance (ANCOVA) was used to explore the main effects of different interventions on the variables. Pre-test data was used for the covariate. If significant effects were found, Bonferroni post-hoc tests were performed. In addition, data of gene expression changes were calculated by $2^{-\Delta \Delta C T}$ and analyzed by ANOVA. To define the magnitude and direction of the linear relationship between survival-related gene expression with cortisol, anxiety, and VD, the bivariate Pearson correlation coefficient ( $r$ ) was calculated on the magnitude of changes. The magnitude of changes was determined by subtracting post-test values from pretest values. Effect sizes (ES) were also computed as the change score divided by the SD of the change score to examine the magnitude of differences while controlling for the influence of the sample size [39] with $<0.2$ considered as a small ES, $0.2-0.5$ as a moderate ES, 0.5-0.8 as a large ES, and $>0.8$ as a very large ES. The percentage changes were calculated by subtracting the pre-test from the post-test divided by the pre-test multiplied by 100 . The significance level was set at $p \leq 0.05$.

\section{Results}

Table 2 provides descriptive data of performance and psychological indicators as well as the changes in VD levels. There were no significant differences between groups in all variable levels at the baseline $(p>0.05)$. A 12-week VD supplementation period led to a significant increase in VD levels, and a significant difference was observed between both groups who received high VD dose and $\mathrm{Y}+\mathrm{LD}$ group $(\mathrm{F}=6.5, p=0.005, \eta \mathrm{p} 2=0.33)$. A 12-week yoga training significantly decreased body fat percentage, as evidenced in the $\mathrm{Y}+\mathrm{HD}$ and $\mathrm{Y}+\mathrm{LD}$ groups compared to the HD group with moderate effect size $(\mathrm{F}=7.2$, $p<0.003, \eta p 2=0.36$ ). We observed that there were significant differences between groups at shoulder flexibility (Ipsilateral: $\mathrm{F}=7.8, p=0.002, \eta \mathrm{p} 2=0.38$; Contralateral: $\mathrm{F}=6.4 p=0.005, \eta \mathrm{p} 2=0.33$ ), and Rockport walking test

Table 2 Performance and psychological indicators of participants before and after performing the intervention

\begin{tabular}{|c|c|c|c|c|c|c|}
\hline Variable & Group & Pre & Post & $\%$ change & $P$ within & $P$ between \\
\hline \multirow[t]{3}{*}{ Vitamin D (IU) } & $\mathrm{HD}$ & $41.2 \pm 16.2$ & $53.5 \pm 15.9$ & 34.62 & 0.001 & 0.005 \\
\hline & $Y+H D$ & $44.8 \pm 13.1$ & $57.5 \pm 12.3$ & $32.17 \#$ & 0.001 & \\
\hline & $Y+L D$ & $43.4 \pm 15.1$ & $49.3 \pm 16.2$ & $15.69^{*}$ & 0.001 & \\
\hline \multirow[t]{3}{*}{ Body fat percentage (\%) } & $\mathrm{HD}$ & $37.0 \pm 4.4$ & $36.8 \pm 4.3$ & -0.52 & 0.343 & 0.003 \\
\hline & $Y+H D$ & $34.8 \pm 3.3$ & $33.4 \pm 2.9$ & $-3.94^{*}$ & 0.003 & \\
\hline & $Y+L D$ & $37.0 \pm 4.1$ & $35.3 \pm 4.3$ & $-4.67^{*}$ & 0.001 & \\
\hline \multirow[t]{3}{*}{ Rockport walk test (s) } & $\mathrm{HD}$ & $1129.7 \pm 118.0$ & $1132.2 \pm 106.8$ & 0.33 & 0.774 & 0.001 \\
\hline & $Y+H D$ & $1106.1 \pm 84.5$ & $1048.9 \pm .32 .2$ & $-5.00^{*}$ & 0.018 & \\
\hline & $Y+L D$ & $1112.2 \pm 46.9$ & $1059.1 \pm 46.9$ & $-4.75^{*}$ & 0.001 & \\
\hline \multicolumn{7}{|l|}{ Shoulder flexibility $\left({ }^{\circ}\right)$} \\
\hline Ips & $\mathrm{HD}$ & $125.4 \pm 18.0$ & $125.4 \pm 17.8$ & 0.04 & 0.991 & Ips: \\
\hline Con & & $231.1 \pm 19.1$ & $231.1 \pm 18.9$ & 0.01 & 0.991 & 0.002 \\
\hline Ips & $Y+H D$ & $125.9 \pm 14.0$ & $139.8 \pm 12.8$ & $11.9^{*}$ & 0.013 & Con: \\
\hline Con & & $234.1 \pm 14.0$ & $220.2 \pm 12.8$ & $-5.8^{*}$ & 0.013 & 0.005 \\
\hline Ips & $Y+L D$ & $127.7 \pm 11.7$ & $138.8 \pm 8.9$ & $9.1^{*}$ & 0.001 & \\
\hline Con & & $230.8 \pm 10.8$ & $220.7 \pm 8.5$ & $-4.3^{*}$ & 0.001 & \\
\hline \multirow[t]{3}{*}{ Anxiety (U.A) } & $\mathrm{HD}$ & $16.3 \pm 9.3$ & $16.1 \pm 9.1$ & 0.02 & 0.343 & 0.001 \\
\hline & $Y+H D$ & $17.3 \pm 9.5$ & $8.1 \pm 6.4$ & $-56.53^{*}$ & 0.003 & \\
\hline & $Y+L D$ & $14.2 \pm 9.1$ & $6.8 \pm 5.1$ & $-49.44^{*}$ & 0.002 & \\
\hline \multirow[t]{3}{*}{ Cortisol ( $\mu \mathrm{g} / \mathrm{dl})$} & $\mathrm{HD}$ & $16.2 \pm 5.8$ & $21.9 \pm 9.4$ & 33.5 & 0.073 & 0.397 \\
\hline & $Y+H D$ & $16.3 \pm 4.7$ & $19.8 \pm 6.5$ & 19.3 & 0.084 & \\
\hline & $Y+L D$ & $20.0 \pm 6.5$ & $22.2 \pm 5.3$ & 15.3 & 0.198 & \\
\hline
\end{tabular}

$H D$, high dose of vitamin $D$ group; $Y+H D$, yoga with a high dose of vitamin $D$ group; $Y+L D$, yoga with a low dose of vitamin $D$ group. Ips, Ipsilateral, Con; Contralateral

*Significant difference with HD group

\# Significant difference with Y + LVD group 
with moderate effect size $(\mathrm{F}=12.4, p<0.001, \eta p 2=0.49)$. The Bonferroni post hoc test showed that shoulder flexibility and Rockport walk tests significantly improved both the $\mathrm{Y}+\mathrm{HD}$ and $\mathrm{Y}+\mathrm{LD}$ groups than the HD group $(p<0.05)$.

A significant difference in anxiety was observed between groups with a moderate effect size $(\mathrm{F}=14.2$, $p<0.001, \eta p 2=0.52$ ). A 12 -week yoga training was more useful to reduce anxiety in both the $\mathrm{Y}+\mathrm{HD}$ and $\mathrm{Y}+\mathrm{LD}$ groups than in the HD group. There were no significant changes in anxiety in the HD group $(p>0.05)$ (Table 1$)$. Further, there was no significant difference between groups at the cortisol level with a relatively low effect size $(\mathrm{F}=0.95, p=0.397, \eta \mathrm{p} 2=0.07)$ (Table 2).

Figure 1a shows P53 was over-expressed in all groups after the intervention; a significant difference was observed in leukocyte's P53 expression between the groups $(\mathrm{F}=7.1, p=0.003)$. The Bonferroni post hoc test showed a significant difference was between the $\mathrm{Y}+\mathrm{HD}$ group and $\mathrm{Y}+\mathrm{LD}(p=0.002)$.

Data appeared that leukocyte's NF-kB expression was down-regulated in all groups following the intervention, but this change was not statistically significant between groups $(\mathrm{F}=1.5 \cdot p=0.231)$ (Fig. $1 \mathrm{~b})$.
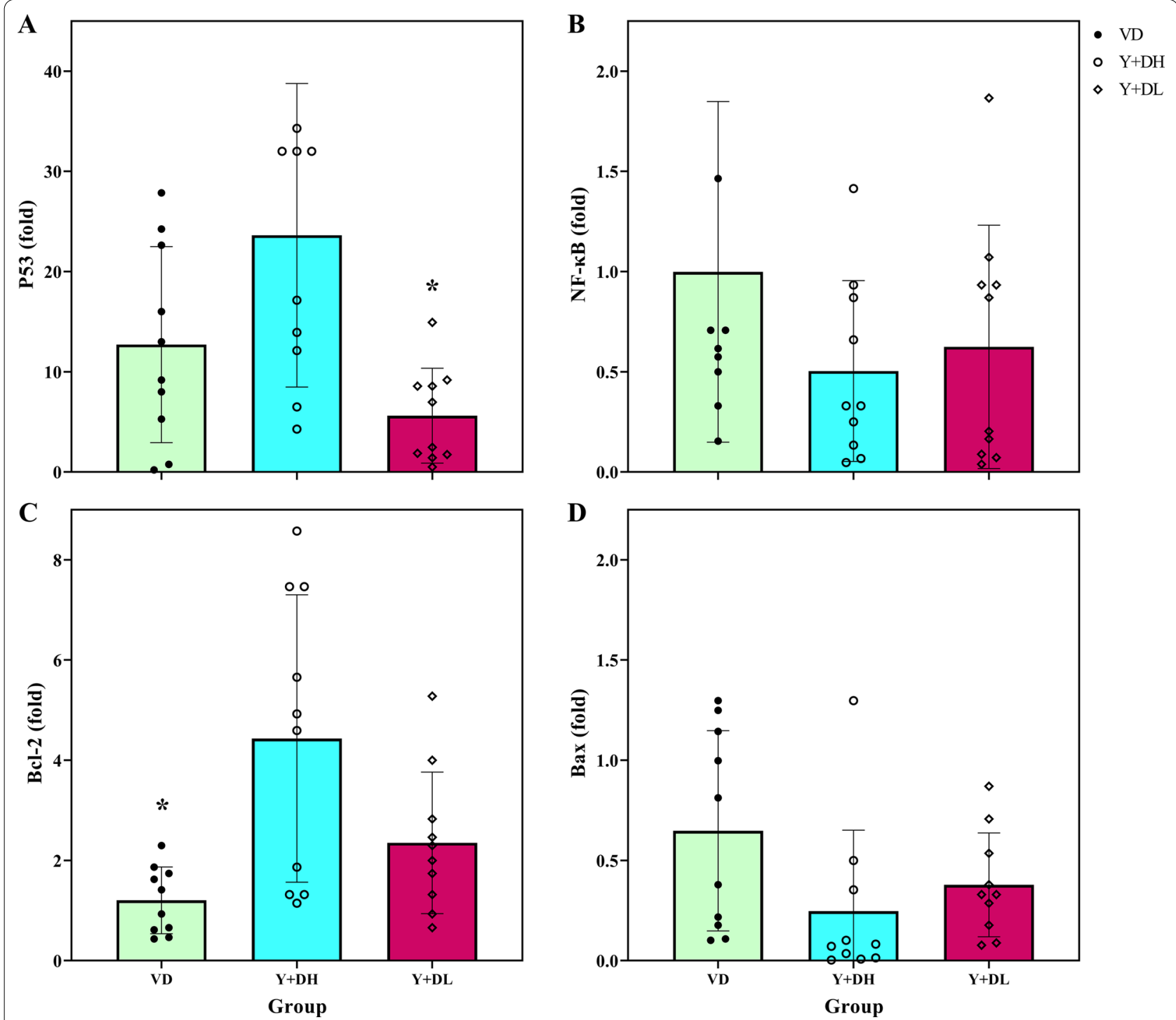

Fig. 1 Gene expression of p53 (a), Bcl2 (b), NF-kB (c) and Bax (d) at baseline and after intervention in peripheral blood cells. VD: high dose of vitamin $D, Y+D L$ : yoga with a low dose of vitamin $D, Y-D H$ : yoga with a high dose of vitamin $D$. * Significant difference from pre-to post intervention 
A 12-week of yoga training led to up-regulate $\mathrm{Bcl} 2$ expression in all groups after intervention. There was a significant difference in leukocyte's Bcl2 expression between the groups) $\mathrm{F}=7.5, p=0.003$ ). The Bonferroni post hoc test showed a significant difference was between the $\mathrm{Y}+\mathrm{HD}$ group and $\mathrm{HD}(p=0.002)$ (Fig. 1c).

We observed that leukocyte Bax expression was downregulated in all groups following the intervention, but there was no significant difference between groups $(\mathrm{F}=2.6 . p=0.091)$ (Fig. 1d).

Table 3 presented the correlation between changes in leukocyte survival-related gene expressions and anxiety, VD, and cortisol levels after the intervention. Anxiety level had a significant positive relationship with NF- $\kappa B$ and Bax expression and was negatively associated with p53 and Bcl2 expression. Cortisol level had a significant positive correlation with NF- $\mathrm{kB}$ expression and a negative correlation with p53 and $\mathrm{Bcl} 2$ expression. In addition, VD only correlated with p53 and Bcl2 expression.

The intensity of initial sessions was considered low, but a moderate intensity was achieved towards the protocol's end. The range of the Borg scale was 8-14.

\section{Discussion}

The main aim of this research was to evaluate the efficacy of a 12-week yoga training combined with the high dose of VD supplementation on physical performance and genes involved in the survival of immune cells of $\mathrm{BC}$ survivors. The high dose of VD supplementation led to significant increases in VD level than the low VD dose. The findings revealed that yoga training combined with the high VD supplementation improved anxiety and the physical fitness of $\mathrm{BC}$ survivors, not the high VD amount alone. Participants who received the high dose of VD showed up-regulation of leukocytes P53 \& $\mathrm{Bcl} 2$ genes involved in cell survival. A down-regulation trend was observed in apoptosis genes (NF- $\mathrm{kB} \& \mathrm{Bax}$ ) that were not statistically significant between groups. No change in the circulatory level of cortisol was observed. Moreover, our findings demonstrated that a

Table 3 Pearson correlation coefficient $(r$ ) between changes in survival-related gene expression and anxiety, vitamin D, and cortisol after the intervention

\begin{tabular}{lccc}
\hline Variables & $\boldsymbol{\Delta}$ anxiety & $\boldsymbol{\Delta}$ VD & $\boldsymbol{\Delta}$ Cortisol \\
\hline P53 & $-0.43^{*}$ & $0.79^{*}$ & $-0.42^{*}$ \\
BCl2 & $-0.64^{*}$ & $0.54^{*}$ & $-0.54^{*}$ \\
NF-KB & $0.39^{*}$ & -0.29 & $0.62^{*}$ \\
Bax & $0.42^{*}$ & -0.29 & 0.15
\end{tabular}

VD, vitamin D

*Significant correlation $(p<0.05)$ combination of yoga with a low dose of VD supplementation improved anxiety and the selected physical fitness indicators but did not show synergistic effects on gene expression involved in cell survival in peripheral blood cells. Therefore, our findings indicate that BC survivors could benefit from yoga training combined with a high dose of VD supplementation, as evidenced by improvements in physical and psychological measures and gene expression involved in cell survival in leukocytes.

Cancer-related fatigue has been shown to negatively affect physical activity, leading to adverse changes in body composition. Our finding showed that a 12-week yoga training reduced body weight and body fat percentage compared to the HD group, which is supported by the previous studies showing that regular yoga training can reduce body fat and positively affect body composition [40-42]. Littman et al. [41] reported body fat and waist circumference reduced in overweight and obese $\mathrm{BC}$ survivors following a six-month yoga training. Exercise training and healthy nutrition reduce body weight by lowering abdominal and subcutaneous fat via increasing metabolic expenditure, leading to improved body composition [43]. Therefore, yoga seems to be effective in weight loss and reducing body fat percentage.

Research has shown depression and anxiety are the most BC complications [44]. Fear of recurrence, death, and the side effects of treatments disturb the mental state and cause anxiety, negatively affecting the Qol of $\mathrm{BC}$ survivors. Our finding demonstrated that although the decreased cortisol levels after intervention were not significant intergroup, the anxiety level was significantly reduced in both yoga groups. There also were significant associations between anxiety level and survival-related genes. Changing the blood indicators of the psychological state, cortisol, may take more than three months. However, yoga is a practical approach for individuals with elevated anxiety levels [45], particularly for BC patients [46]. Although the precise mechanisms of yoga on anxiety are unclear, however, several hypotheses have been proposed. Given that the yoga training was held in groups and perhaps the feeling of empathy, sharing problems, and improving social behaviors could have to some extent, resulted in reducing the anxiety [46]. In addition, yoga exercises include meditation, which leads to improved emotional health through learning how to relax, thereby reduces anxiety. Moreover, from a molecular point, yoga promotes brain health by increasing brain-derived neurotrophic factor (BDNF) [47]) which is a crucial neurotrophin in the management of mood disorders [48]. Therefore, yoga is generally effective in improving mood state, but the manifestation of this condition in the blood takes more time. 
Surgery and chemotherapy can exaggerate fatigue, reduce aerobic fitness, and decline the flexibility of the joints, especially the shoulder girdle on the affected side [49]. Collectively, these changes result in a decline in quality of life. Our findings showed significant improvements in flexibility and aerobic fitness following the yoga training program. Consistent with our findings, previous studies reported that yoga training significantly improves shoulder range of motion [50,51]. Improving the flexibility of the shoulder girdle in the present study is expected due to the nature of yoga movements are stretchingmuscular endurance movements. However, improved aerobic fitness with yoga was an interesting finding of this study, given that the intensity of training remained low to moderate during the interventions, and yoga is not primarily specific to improving aerobic fitness. However, the patients' baseline aerobic fitness was low, which could be attributed to fatigue resulting from cancer and chemotherapy. Participating in yoga training for 12 weeks may have sufficient to improve aerobic fitness.

Apoptosis is a sophisticated process that is tightly regulated by the equilibrium of apoptotic and anti-apoptotic genes. NF- $\mathrm{kB}$ and $\mathrm{p} 53$ are the primary regulators of cell survival and can be activated by the different stimuli; the interactions of these two genes and their downstream pathways are critical for cell fate decisions. Previous research has revealed that physical training and VD supplementation can modify this cellular interaction [19, 31]. Our finding showed that yoga training combined with the high dose of VD supplementation significantly upregulated leukocytes $\mathrm{P} 53$ and $\mathrm{Bcl} 2$ while no significant downregulation in NF- $\mathrm{kB}$ and Bax was found. Although downregulation in NF- $\mathrm{kB}$ and Bax were not statistically significant, which might be due to the short duration of the study, it was clinically valuable. Studies reported that treatment with VD down-regulates NF-KB expression in human lymphocytes [20, 21]. Also, Gupta et al. [19] demonstrated that treatment with VD improved cell survival after ultraviolet radiation by increasing p53 expression. This effect was dose-dependent. The up-regulation of the p53 gene induces cell cycle arrest and repair of DNA, hence increased cell survival [52]. Moreover, a study showed a high dose of VD led to an increase in Bcl-2 expression [53]. In this regard, Wang et al. reported incubating VD to thyrocytes induced the expression of $\mathrm{Bcl} 2$ but did not affect the expression of Bax [54]. They suggested that an elevated $\mathrm{Bcl} / \mathrm{Bax}$ ratio may protect leukocytes from apoptosis. On the other hand, physical exercise may be effective in the apoptosis process. In this regard, Ram et al. [55] compare the lymphocyte apoptotic index and DNA damage of trained yoga practitioners with $\mathrm{BC}$ patients. They reported that apoptosis and DNA damage of lymphocytes were less in the yoga group than in the non-yoga group [55]. Therefore, performing yoga with a high dose of VD supplementation, not a low dose, will help improve the function of immune cells by modifying gene expression involved in the apoptosis process.

This study contains some limitations. First, it was difficult to monitor the participants' dietary intake, and we could not quantify the amount of VD taken from the diet. Second, monitoring the intensity of yoga and individualizing yoga's intensity is complicated; however, the Borg scale, which demonstrates the general feeling and the degree of the mental and physical difficulty of the work done, was used, which merits some limitations. We did not observe significant changes in some molecular markers; therefore, further research focusing on longer training intervention time-varying in intensities and higher dosage of VD supplementation is warranted.

\section{Conclusion and implication}

In conclusion, combining yoga training with a high dose of VD supplementation has further benefits on some crucial molecular markers of immune cell survival, physical and psychological status of $\mathrm{BC}$ survivors. Therefore, $B C$ survivors would be encouraged to perform yoga training and also simultaneously consume a high dose of VD supplementation, not low doses, to obtain more health benefits.

\section{Abbreviations \\ BC: Breast cancer; Qol: Quality of life; IL-6: Interleukin-6; IL-10: Interleukin-10; TNF-a: Tumor necrosis factor-a; PBMCs: Peripheral blood mononuclear cells; VD: Vitamin D; HVD: High dose of VD; Y-HVD: Yoga with a high dose of VD; Y-LVD: Yoga with a low dose of VD; BF\%: Body fat percentage; RPE: Rating of perceived exertion; ANCOVA: Analysis of covariance; ES: Effect sizes.}

\section{Acknowledgements}

The authors would like to acknowledge all participants and a yoga teacher of Payammehr yoga center who collaborated with us.

\section{Authors' contributions}

SA-S: Conceptualization, Methodology, Supervision, Formal analysis, Writingoriginal draft; MK: Conceptualization, Supervision, Writing - review \& editing; VK-Z: Methodology, Data curation, Writing_original draft; MJ: Methodology, Writing-original draft, Data curation. All authors read and approved the final manuscript.

\section{Funding}

There was no funding support.

\section{Availability of data and materials}

Data would be available from the corresponding author on reasonable request.

\section{Declarations}

Ethics approval and consent to participate

The ethics committee of Sport Sciences Research Institute of Iran (approval number: IR.SSRI.REC.1398.111) approved all research procedures, and this study was conducted under the Declaration of Helsinki. 


\section{Consent for publication \\ Not applicable.}

\section{Competing interests}

The authors declare that they have no competing interests.

\section{Author details}

${ }^{1}$ Department of Exercise Physiology, Faculty of Physical Education and Sports Science, Kharazmi University, Tehran, Iran. ${ }^{2}$ School of Nutrition and Dietetics, Faculty of Pure and Applied Science, Acadia University, Wolfville, NS, Canada.

Received: 14 June 2021 Accepted: 18 August 2021

Published online: 28 August 2021

\section{References}

1. Tsaras K, Papathanasiou IV, Mitsi D, Veneti A, Kelesi M, Zyga S, Fradelos EC. Assessment of depression and anxiety in breast cancer patients: prevalence and associated factors. Asian Pac J Cancer Prev. 2018;19:1661-9.

2. Lovelace DL, McDaniel LR, Golden D. Long-term effects of breast cancer surgery, treatment, and survivor care. J Midwifery Womens Health. 2019;64:713-24.

3. Solomayer EF, Feuerer M, Bai L, Umansky V, Beckhove P, Meyberg GC, Bastert G, Schirrmacher V, Diel IJ. Influence of adjuvant hormone therapy and chemotherapy on the immune system analysed in the bone marrow of patients with breast cancer. Clin Cancer Res. 2003;9:174-80.

4. Steele TA. Chemotherapy-induced immunosuppression and reconstitution of immune function. Leuk Res. 2002;26:411-4.

5. Kang D-H, Weaver MT, Park N-J, Smith B, McArdle T, Carpenter J. Significant impairment in immune recovery following cancer treatment. Nurs Res. 2009;58:105-14.

6. Lukin DJ, Carvajal LA, Liu W-J, Resnick-Silverman L, Manfredi JJ. p53 Promotes cell survival due to the reversibility of its cell-cycle checkpoints. Mol Cancer Res. 2015:13:16-28.

7. Donehower LA, Harvey M, Slagle BL, McArthur MJ, Montgomery CA, Butel JS, Bradley A. Mice deficient for p53 are developmentally normal but susceptible to spontaneous tumours. Nature. 1992;356:215-21.

8. Liu T, Zhang L, Joo D, Sun S-C. NF-kB signaling in inflammation. Signal Transduct Target Ther. 2017;2:17023.

9. Karin M. NF-kappaB as a critical link between inflammation and cancer. Cold Spring Harbor Perspect Biol. 2009;1:a000141.

10. Li L, Wu W, Huang W, Hu G, Yuan W, Li W. NF-kB RNAi decreases the Bax/ $\mathrm{BCl}-2$ ratio and inhibits TNF-a-induced apoptosis in human alveolar epithelial cells. Inflamm Res. 2013;62:387-97.

11. Mohan S, Abdelwahab SI, Kamalidehghan B, Syam S, May KS, Harmal NS, Shafifiyaz N, Hadi AH, Hashim NM, Rahmani M, et al. Involvement of NF-KB and $\mathrm{BCl}$ 2/Bax signaling pathways in the apoptosis of MCF7 cells induced by a xanthone compound Pyranocycloartobiloxanthone A. Phytomedicine. 2012;19:1007-15.

12. Bower JE, Ganz PA, Irwin MR, Arevalo JMG, Cole SW. Fatigue and gene expression in human leukocytes: increased NF-KB and decreased glucocorticoid signaling in breast cancer survivors with persistent fatigue. Brain Behav Immun. 2011;25:147-50.

13. Morris G, Maes M. Increased nuclear factor-kB and loss of p53 are key mechanisms in myalgic encephalomyelitis/chronic fatigue syndrome (ME/CFS). Med Hypotheses. 2012;79:607-13.

14. Movahed S, Varshoee Tabrizi F, Pahlavani N, Seilanian Toussi M, Motlagh A, Eslami S, Ghayour-Mobarhan M, Nematy M, Ferns GA, Emadzadeh M, et al. Comprehensive assessment of nutritional status and nutritionalrelated complications in newly diagnosed esophageal cancer patients: a cross-sectional study. Clin Nutr. 2021;40:4449-55.

15. Pahlavani N, Malekahmadi M, Firouzi S, Rostami D, Sedaghat A, Moghaddam AB, Ferns GA, Navashenaq JG, Reazvani R, Safarian M, Ghayour-Mobarhan M. Molecular and cellular mechanisms of the effects of Propolis in inflammation, oxidative stress and glycemic control in chronic diseases. Nutr Metab. 2020;17:65.

16. Nechuta S, Lu W, Chen Z, Zheng Y, Gu K, Cai H, Zheng W, Shu XO. Vitamin supplement use during breast cancer treatment and survival: a prospective cohort study. Cancer Epidemiol Biomark Prev. 2011;20:262-71.
17. Peppone LJ, Rickles AS, Janelsins MC, Insalaco MR, Skinner KA. The association between breast cancer prognostic indicators and serum 25-OH vitamin D levels. Ann Surg Oncol. 2012;19:2590-9.

18. Goodwin PJ, Ennis M, Pritchard KI, Koo J, Hood N. Prognostic effects of 25-hydroxyvitamin D levels in early breast cancer. J Clin Oncol. 2009;27:3757-63.

19. Gupta R, Dixon KM, Deo SS, Holliday CJ, Slater M, Halliday GM, Reeve VE, Mason RS. Photoprotection by 1,25 dihydroxyvitamin D3 Is associated with an increase in p53 and a decrease in nitric oxide products. J Investig Dermatol. 2007;127:707-15.

20. Geldmeyer-Hilt K, Heine G, Hartmann B, Baumgrass R, Radbruch A, Worm M. 1,25-dihydroxyvitamin D3 impairs NF-kB activation in human naïve B cells. Biochem Biophys Res Commun. 2011;407:699-702.

21. Yu XP, Bellido T, Manolagas SC. Down-regulation of NF-kappa B protein levels in activated human lymphocytes by 1,25-dihydroxyvitamin D3. Proc Natl Acad Sci U S A. 1995:92:10990-4.

22. Tabasi N, Rastin M, Mahmoudi M, Ghoryani M, Mirfeizi Z, Rabe SZT, Reihani H. Influence of vitamin D on cell cycle, apoptosis, and some apoptosis related molecules in systemic lupus erythematosus. Iran J Basic Med Sci. 2015;18:1107-11.

23. Swami S, Raghavachari N, Muller UR, Bao YP, Feldman D. Vitamin D growth inhibition of breast cancer cells: gene expression patterns assessed by cDNA microarray. Breast Cancer Res Treat. 2003;80:49-62.

24. Crew KD, Xiao T, Thomas PS, Terry MB, Maurer M, Kalinsky K, Feldman S, Brafman L, Refice SR, Hershman DL. Safety, feasibility, and biomarker effects of high-dose vitamin D supplementation among women at high risk for breast cancer. Int J Food Sci Nutr Diet. 2015:2015:1-16.

25. Cramer H, Lange S, Klose P, Paul A, Dobos G. Yoga for breast cancer patients and survivors: a systematic review and meta-analysis. BMC Cancer. 2012;12:412.

26. Smith KB, Pukall CF. An evidence-based review of yoga as a complementary intervention for patients with cancer. Psychooncology. 2009:18:465-75.

27. Balaji P, Varne SR, Ali SS. Physiological effects of yogic practices and transcendental meditation in health and disease. N Am J Med Sci. 2012:4:442.

28. Yadav RK, Magan D, Mehta N, Sharma R, Mahapatra SC. Efficacy of a short-term yoga-based lifestyle intervention in reducing stress and inflammation: preliminary results. J Altern Complement Med. 2012;18:662-7.

29. Morey JN, Boggero IA, Scott AB, Segerstrom SC. Current directions in stress and human immune function. Curr Opin Psychol. 2015:5:13-7.

30. Kiecolt-Glaser JK, Christian L, Preston H, Houts CR, Malarkey WB, Emery CF, Glaser R. Stress, inflammation, and yoga practice. Psychosom Med. 2010;72:113-21.

31. Gopal A, Mondal S, Gandhi A, Arora S, Bhattacharjee J. Effect of integrated yoga practices on immune responses in examination stress-a preliminary study. Int J Yoga. 2011:4:26.

32. Black DS, Cole SW, Irwin MR, Breen E, St Cyr NM, Nazarian N, Khalsa DS, Lavretsky $\mathrm{H}$. Yogic meditation reverses NF-KB and IRF-related transcriptome dynamics in leukocytes of family dementia caregivers in a randomized controlled trial. Psychoneuroendocrinology. 2013;38:348-55.

33. Molanouri Shamsi M, Hassan ZM. Chapter 42-Exercise, selenium, and cancer cells. In: Preedy VR, Patel VB, editors. Cancer (Second Edition). San Diego: Academic Press; 2021. p. 475-82.

34. Papp ME, Lindfors P, Nygren-Bonnier M, Gullstrand L, Wändell PE. Effects of high-intensity hatha yoga on cardiovascular fitness, adipocytokines, and apolipoproteins in healthy students: a randomized controlled study. J Altern complement Med (New York, NY). 2016;22:81-7.

35. Jackson AS, Pollock ML, Ward A. Generalized equations for predicting body density of women. Med Sci Sports Exerc. 1980;12:175-81.

36. Seneli RM, Ebersole KT, O'Connor KM, Snyder AC. Estimated V(O2)max from the rockport walk test on a nonmotorized curved treadmill. J Strength Cond Res. 2013:27:3495-505.

37. Cheema BS, Gaul CA. Full-body exercise training improves fitness and quality of life in survivors of breast cancer. J Strength Cond Res. 2006;20:14-21.

38. Ke Y, Ng T, Yeo HL, Shwe M, Gan YX, Chan A. Psychometric properties and measurement equivalence of the English and Chinese versions of the Beck Anxiety Inventory in patients with breast cancer. Support Care Cancer. 2017:25:633-43. 
39. Dankel SJ, Loenneke JP. Effect sizes for paired data should use the change score variability rather than the pre-test variability. J Strength Cond Res 2018.

40. Hughes DC, Darby N, Gonzalez K, Boggess T, Morris RM, Ramirez AG. Effect of a six-month yoga exercise intervention on fitness outcomes for breast cancer survivors. Physiother Theory Pract. 2015;31:451-60.

41. Littman AJ, Bertram LC, Ceballos R, Ulrich CM, Ramaprasad J, McGregor B, McTiernan A. Randomized controlled pilot trial of yoga in overweight and obese breast cancer survivors: effects on quality of life and anthropometric measures. Support Care Cancer. 2012;20:267-77.

42. Cramer $\mathrm{H}$, Thoms MS, Anheyer D, Lauche R, Dobos G. Yoga in women with abdominal obesity — a randomized controlled trial. Dtsch Arztebl Int. 2016:113:645-52.

43. Swift DL, MCGee JE, Earnest CP, Carlisle E, Nygard M, Johannsen NM. The effects of exercise and physical activity on weight loss and maintenance. Prog Cardiovasc Dis. 2018;61:206-13.

44. Burgess C, Cornelius V, Love S, Graham J, Richards M, Ramirez A. Depression and anxiety in women with early breast cancer: five year observational cohort study. BMJ. 2005;330:702.

45. Cramer H, Lauche R, Anheyer D, Pilkington K, de Manincor M, Dobos G, Ward L. Yoga for anxiety: a systematic review and meta-analysis of randomized controlled trials. Depress Anxiety. 2018;35:830-43.

46. Ülger Ö, Yağıı NV. Effects of yoga on the quality of life in cancer patients. Complement Ther Clin Pract. 2010;16:60-3.

47. Cahn BR, Goodman MS, Peterson CT, Maturi R, Mills PJ. Yoga, meditation and mind-body health: increased BDNF, cortisol awakening response, and altered inflammatory marker expression after a 3-month yoga and meditation retreat. Front Hum Neurosci. 2017;11:315.

48. Polyakova M, Stuke K, Schuemberg K, Mueller K, Schoenknecht P, Schroeter ML. BDNF as a biomarker for successful treatment of mood disorders: a systematic and quantitative meta-analysis. J Affect Disord. 2015; 174:432-40
49. Hidding JT, Beurskens $\mathrm{CH}$, van der Wees $\mathrm{PJ}$, Laarho ven van $\mathrm{HW}$ Nijhuis-vander Sanden MW. Treatment related impairments in arm and shoulder in patients with breast cancer: a systematic review. PLoS ONE. 2014;9:96748

50. Mazor M, Lee JQ, Peled A, Zerzan S, Irwin C, Chesney MA, Serrurier K, Sbitany H, Dhruva A, Sacks D. The effect of yoga on arm volume, strength, and range of motion in women at risk for breast cancer-related lymphedema. J Altern Complement Med. 2018;24:154-60.

51. Galantino ML, Cannon N, Hoelker T, Quinn L, Greene L. Effects of lyengar yoga on measures of cognition, fatigue, quality of life, flexibility, and balance in breast cancer survivors: a case series. Rehabil Oncol. 2008;26:18.

52. Li G, Mitchell DL, Ho VC, Reed JC, Tron VA. Decreased DNA repair but normal apoptosis in ultraviolet-irradiated skin of p53-transgenic mice. Am J Pathol. 1996:148:1113-23.

53. De Haes P, Garmyn M, Carmeliet G, Degreef H, Vantieghem K, Bouillon $R$, Segaert $S$. Molecular pathways involved in the anti-apoptotic effect of 1,25-dihydroxyvitamin D3 in primary human keratinocytes. J Cell Biochem. 2004;93:951-67.

54. Wang SH, Koenig RJ, Giordano TJ, Myc A, Thompson NW, Baker JR Jr. 1 a, 25-Dihydroxyvitamin D3 up-regulates $\mathrm{BCl}$-2 expression and protects normal human thyrocytes from programmed cell death. Endocrinology. 1999;140:1649-56.

55. Ram A, Banerjee B, Hosakote VS, Rao RM, Nagarathna R. Comparison of lymphocyte apoptotic index and qualitative DNA damage in yoga practitioners and breast cancer patients: a pilot study. Int J Yoga. 2013;6:20-5.

\section{Publisher's Note}

Springer Nature remains neutral with regard to jurisdictional claims in published maps and institutional affiliations.
Ready to submit your research? Choose BMC and benefit from:

- fast, convenient online submission

- thorough peer review by experienced researchers in your field

- rapid publication on acceptance

- support for research data, including large and complex data types

- gold Open Access which fosters wider collaboration and increased citations

- maximum visibility for your research: over $100 \mathrm{M}$ website views per year

At BMC, research is always in progress.

Learn more biomedcentral.com/submissions 